\title{
Detecting and Differentiating Phytoplasmas Belonging to Subgroups 16SrlV-A and 16SrIV-D Associated With Lethal Declines of Palms in Florida Using qPCR and High-Resolution Melt Analysis (HRMA)
}

Brian W. Bahder and Ericka E. Helmick, Department of Entomology and Nematology, University of Florida, Davie, 33314-7719; and Nigel A. Harrison, Department of Plant Pathology, University of Florida, Davie, 33314-7719

\begin{abstract}
Lethal yellowing (LY) and Texas Phoenix palm decline (TPPD) are two important phytoplasma diseases of palms in Florida. Both have been responsible for major economic losses historically and remain a constant threat to the sustainability of palm production in the landscaping and nursery industries in Florida. These two diseases cause rapid, lethal decline in afflicted palms, so rapid detection and identification is crucial to implement appropriate management strategies to reduce further spread and losses. In this study, a qPCR assay was developed to detect and identify the causal agents of LY and TPPD. Based on sequence data of the $16 \mathrm{~S}$ gene for

the 16SrIV-A phytoplasma (LY) and the 16SrIV-D phytoplasma (TPPD), two regions were identified in the gene that possessed sufficient variation to yield amplicons with measurable differences in melting temperature based on high resolution melt analysis (HRMA). One region was in the $5^{\prime}$ region and the other was located in the $3^{\prime}$ region of the gene. Products from both regions yielded amplicons with significantly different melting temperatures between the two phytoplasma strains. This research allows for the detection and identification of phytoplasmas in palms rapidly by eliminating many lengthy and post-PCR steps commonly used in phytoplasma identification.
\end{abstract}

Lethal yellowing (LY) of coconut palms (Cocos nucifera L.) is a disease caused by a phytoplasma belonging to the $16 \mathrm{~S}$ rRNA-encoding gene RFLP group16SrIV, subgroup A (16SrIV-A). This devastating disease was first described in 1891 at Montego Bay, Jamaica (Fawcett 1891). It was first reported in Florida from Key West in 1955 (Corbett 1959) and has been responsible for the loss of millions of coconut palms throughout the Caribbean (Arellano and Oropeza 1995), likely since before its discovery to current day, where it still remains a threat to the sustainability of coconut palm production in the region, both for ornamental and agricultural purposes. In addition to coconut palms, LY is known to infect and have negligible effects on at least 36 other species of palm (Harrison and Elliott 2015), including various species in the genera Phoenix and Pritchardia, both of which are important ornamental groups.

Another phytoplasma disease of palms in the New World has been termed Texas Phoenix palm decline (TPPD), so called because it was first described over 30 years ago in Texas (McCoy et al. 1980) and belongs to the $16 \mathrm{SrIV}$ group, subgroup D. TPPD was discovered in Florida in 2006 (Harrison et al. 2008), where the disease was initially centered on the central west coast of Florida. Initially, TPPD was known to infect Phoenix spp. Palms; however, it had been reported in cabbage palm (Sabal palmetto) (Harrison et al. 2009) and has since been well documented throughout Florida in Phoenix spp. palms as well as S. palmetto (Harrison and Elliott 2016).

Both LY and TPPD cause rapid declines in palms that lead to death of the plant, which can occur as quickly as 3 to 5 months after the onset of symptoms (Harrison and Elliott 2015). Due to the rapid decline and death of palms, fast detection and identification of the phytoplasma involved is essential to make the appropriate management decisions in order to prevent further spread of the phytoplasma, whether it be palm removal or treatment with oxytetracycline HCL (OTC). The impetus for having rapid and reliable diagnoses is due to the economic impact that palms have for the state of Florida. Palms in general have a $\$ 404$ million impact on the nursery and landscaping industries in Florida (Khachatryan and Hodges 2014) due to their

Corresponding author: Brian W. Bahder, E-mail: bbahder@ufl.edu

Accepted for publication 11 March 2017.

(c) 2017 The American Phytopathological Society aesthetic appeal and being an iconic sight in tropical and subtropical landscapes. Aside from their value as ornamental plants, coconut palms and the date palm, Phoenix dactylifera, are important agricultural crops as well. Additionally, S. palmetto is a native palm species found in the southeastern United States and the impact that TPPD has on this species highlights the need for rapid detection and identification from an environmental and conservation standpoint as well.

Currently, the detection and identification of phytoplasmas is conducted by PCR and RFLP analysis of the 16S rDNA gene and is the established classification system for all phytoplasmas (Duduk and Bertaccini 2011). This analysis is sometimes supplemented with additional data derived from genes such as $r p$, secY, tuf, and groEL or the 16S-23S intergenic spacer region (Harrison et al. 2002a). While this system, along with genomics work, is essential and highly informative, it is not a practical tool to use for rapid detection and diagnosis of phytoplasmas in order to obtain data that is required by stakeholders, such as homeowners and industry personnel, who need to make rapid management decisions. With advances in molecular genetics and technology, new techniques are becoming available that can be used to increase detection sensitivity and reduce the time and resources involved by eliminating many of the post-PCR steps that are involved in RFLP analyses and nested PCR techniques necessary for working with phytoplasmas in palm trees (Harrison et al. 2002b). One such technology that has the potential to accomplish a faster and more sensitive diagnostic protocol is qPCR coupled with high resolution melt analysis (HRMA). This technique allows for the confirmation that an amplified product from the qPCR assay is the region of interest based on a signature melting temperature that matches a positive control, either a plant with a known phytoplasma infection or a plasmid with the appropriate insert. Once the infection status is known, an evaluation of the melting curve between samples can help distinguish samples that have genetic variation within the region amplified, being sensitive enough to detect single nucleotide polymorphisms (SNPs) (Vossen et al. 2009). The use of HRMA to detect plant pathogens (Bahder et al. 2016; Luchi et al. 2011) and differentiate between strains of various pathogens (Bester et al. 2012; Varga and James 2006) is becoming a common tool in both basic and applied research and could be a valuable tool in rapidly and reliably detecting and identifying phytoplasmas in palm trees. The quicker turnaround for results could ultimately reduce the costs for researchers as well as relieve disease pressures due to the faster accumulation of data, which can be essential for effective management strategies to be implemented faster, thus reducing economic loss. 
The primary objective of the study is to develop primers that are robust enough to amplify both LY and TPPD palm phytoplasma disease agents, and yet still amplify a region that has sufficient genetic variation to be detectable by HRMA as part of the qPCR assays. These primers and assays will then be optimized and standardized so as to replace current diagnostic tools for palm phytoplasmas in Florida, reducing testing costs and time, and allowing for faster dissemination of data to nurseries, government agencies, master gardeners, and homeowners.

\section{Materials and Methods}

Primer design. To identify primer regions, the $16 \mathrm{~S}$ rDNA gene was selected due to its utility in phytoplasma taxonomy. Sequence data were downloaded for the $16 \mathrm{~S}$ gene, $16 \mathrm{~S}$ and $23 \mathrm{~S}$ intergenic region, and 23S gene from GenBank for both LY (accession no. HQ613871.1 and HQ613874.1) and TPPD (AF434989 and HQ613895.1) and aligned using MEGA7 (Kumar et al. 2016). Once aligned, sequences were visually searched for regions where genetic variation existed in the form of gaps (insertions or deletions in LY or TPPD) or the presence of SNPs that result in a change in the number of hydrogen bonds. Once suitable locations were identified, conserved regions at the $5^{\prime}$ and $3^{\prime}$ ends were identified and primers were designed, attempting to possess about $50 \%$ GC content. The Tm of all primers provided in Table 1 are those predicted by manufacturer.

Phytoplasma sample selection. Total DNA extract of palm samples, according to Harrison et al. (1992), received in the University of Florida Plant Pathology Diagnostics Laboratory from local outbreaks of LY and TPPD in Florida that have previously tested positive for the corresponding phytoplasma, sequenced and with their identity verified, were used in this study. Isolates of LY- and TPPDinfected palms used in this study are listed in Table 2. All samples are stored at the University of Florida Fort Lauderdale Research and Education Center (FLREC) in Davie, FL.

PCR and qPCR conditions. All qPCR assays conducted for primer screening, standard optimization, and HRMA of LY and TPPD isolates were performed in $20 \mu$ l reactions composed of $1 \mu \mathrm{l}$ of DNA template, $50 \%$ SsoFast EvaGreen with Low ROX supermix (Bio-Rad, Hercules, CA), 2\% polyvinyl pyrrolidone (MW 40,000) (PVP-40), and $0.15 \mu \mathrm{M}$ of each primer, with the remaining volume made up with nuclease-free water. Thermal cycling conditions for qPCR assays were as follows: initial denaturation at $95^{\circ} \mathrm{C}$ for 2 min followed by 35 cycles of denaturation at $95^{\circ} \mathrm{C}$ for $30 \mathrm{~s}$, annealing at $64^{\circ} \mathrm{C}$ for $30 \mathrm{~s}$, extension at $72^{\circ} \mathrm{C}$ for $15 \mathrm{~s}$ with endpoint detection, followed by HRMA, comprising a denaturation step of $95^{\circ} \mathrm{C}$ for $30 \mathrm{~s}, 55^{\circ} \mathrm{C}$ for $1 \mathrm{~min}$, and $95^{\circ} \mathrm{C}$ for $1 \mathrm{~min}$ with continuous detection on the ramp cycle from $55^{\circ} \mathrm{C}$ to $95^{\circ} \mathrm{C}$ at $1.3^{\circ} \mathrm{C} / \mathrm{s}$ ramp speed. All qPCR reactions were run on a StepOnePlus Real Time PCR System (Applied Biosystems). Standard PCR assays to produce amplicons for cloning and sequencing were performed in $25 \mu \mathrm{l}$, composed of $2 \mu \mathrm{l}$ of DNA template, $0.5 \mu \mathrm{M}$ of each primer, $2 \%$ PVP-40, $200 \mu \mathrm{M}$ dNTPs, $5 \times$ Green GoTaq Flexi buffer, $25 \mathrm{mM}$ $\mathrm{MgCl}_{2}, 1.5 \mathrm{U}$ GoTaq Flexi DNA polymerase, and the remaining volume made up with DNase free water. Thermal cycling conditions were as follows: initial denaturation at $95^{\circ} \mathrm{C}$ for $2 \mathrm{~min}$, followed by 40 cycles of denaturation at $95^{\circ} \mathrm{C}$ for $30 \mathrm{~s}$, annealing at $65^{\circ} \mathrm{C}$ for $30 \mathrm{~s}$, and extension at $72^{\circ} \mathrm{C}$ for $30 \mathrm{~s}$ followed by a final extension of $72^{\circ} \mathrm{C}$ for $5 \mathrm{~min}$. The amplified products were cloned using the TOPO TA Cloning Kit with the pCR 2.1-TOPO plasmids (ThermoFisher Scientific, Waltham, MA). All PCR samples to be sent for sequencing were cleaned using a QIAquick PCR Purification Kit
(Qiagen, Inc.) and eluted in final volume of $30 \mu \mathrm{l}$ of Buffer EB. One microliter of each cleaned PCR product was quantified using a Qubit Fluorometer (ThermoFisher Scientific, Inc.) per the manufacturer's standard protocol. All PCR products were sent to the University of Florida's Interdisciplinary Center for Biotechnology Research (ICBR), in Gainesville, FL, for standard Sanger sequencing. Sequence assembly and trimming were conducted using DNA Baser v2 (HeracleSoftware) and sequences were aligned and concatenated using MEGA v7.0 (Kumar et al. 2016).

Standard preparation and optimization. Primers were initially screened by qPCR using two isolates, Sab1+C for TPPD and EF509 for LY, to determine if the primers could detect both LY and TPPD and if there was a noticeable difference in melting temperature of the amplicons obtained in PCR. Isolates were then tested by standard PCR and the amplicons were visualized on a 1.5\% agarose gel to ensure the target region amplified; these amplicons were then cloned and sequenced in order to produce standards. No nonspecific products were amplified or visualized on the gel that would impact cloning efficiency. Plasmids were subsequently isolated from transformed colonies and quantified using a Qubit Fluorometer (ThermoFisher Scientific, Inc.) per the manufacturer's standard protocol. The plasmid isolation was then diluted to a concentration of $10^{10}$ copies/ $\mu$ l. From this stock, serial dilutions were done until a $10^{1}$ copies/ $\mu$ l solution was obtained. To measure melting temperature differences in the amplified region at different concentrations of template that range from high to low, standards for both LY and TPPD were tested by qPCR with four replicates performed per concentration, resulting in 40 reactions for a given primer set for each phytoplasma strain. Also, five water controls were run alongside plasmid assays as negative controls.

LY and TPPD isolate test. To evaluate the effectiveness of the designed primers to detect LY and TPPD in DNA extracts, five isolates of both LY and TPPD were tested by qPCR at four replicates per isolate. Plasmid standards were run as positive controls as well as to fit the melting curve generated from samples to the melt curve generated by the standards. Total DNA extract from a healthy $S$. palmetto, healthy $C$. nucifera, and a water control were included as negative controls. A one-way ANOVA was performed to evaluate the average difference in melting temperature between subgroup-A and subgroup-D for both primer sets in both the plasmid test and isolate test. The statistical values were calculated using the ANOV function in Microsoft Excel.

Table 2. Isolates of phytoplasmas representing the 16SrIV-A (lethal yellowing) and 16SrIV-D (Texas Phoenix palm decline) taxonomic groupings used to validate primers

\begin{tabular}{llll}
\hline Isolate & Disease & \multicolumn{1}{c}{ Host } & \multicolumn{1}{c}{ Location } \\
\hline EF-509 & LY & Cocos nucifera & Davie, FL, Broward Co. \\
PSA & LY & Cocos nucifera & West Palm Beach, FL, Palm Beach Co. \\
IOJT & LY & Cocos nucifera & Naples, FL, Collier Co. \\
RCP1 & LY & Cocos nucifera & Stewart, FL, Martin Co \\
SWCP & LY & Cocos nucifera & Davie, FL, Broward Co. \\
Sab1+C & TPPD & Sabal palmetto & Sarasota, Manatee Co. \\
RDSOP & TPPD & Sabal palmetto & Safety Harbor, FL, Pinellas Co. \\
DLM & TPPD & Sabal palmetto & Safety Harbor, FL, Pinellas Co. \\
GPL-PS & TPPD & Sabal palmetto & Sarasota, FL, Manatee Co. \\
SP4 & TPPD & Sabal palmetto & Davie, FL, Borward Co. \\
\hline
\end{tabular}

Table 1. Primers designed from the $16 \mathrm{~S}$ rRNA-encoding gene of phyoplasmas associated with lethal yellowing and Texas Phoenix palm decline for use in high resolution melting analysis

\begin{tabular}{|c|c|c|c|c|c|}
\hline Primer & Direction & Sequence $\left(5^{\prime} \rightarrow 3^{\prime}\right)$ & Region & Tm & Product size \\
\hline PP16S-32 & Forward & GGCGGCGTGCTTAATACATG & $5^{\prime}$ & 56.9 & 131 \\
\hline PP16S-163 & Reverse & CCTATCCAGCCTTAGCAAC & $5^{\prime}$ & 52.7 & 131 \\
\hline PP16S-1198 & Forward & GGGCTACAAACGTGATACAATGGC & $3^{\prime}$ & 58.4 & 254 \\
\hline PP16S-1452 & Reverse & TTAGACGATTCCCTCTGCTTRCGC & $3^{\prime}$ & 58.8 & 254 \\
\hline
\end{tabular}




\section{Results}

Primer design. Based on the aligned sequences of the $16 \mathrm{~S}$ gene for both LY and TPPD, two regions were identified that had significant levels of variation (Fig. 1) that appeared different enough to yield different melting temperatures in the amplified product, the first being present in the $5^{\prime}$ region where TPPD had a large insertion $(13 \mathrm{bp})$ of the sequence $5^{\prime}$-GAAATCTTTTAGA-3', which was absent from the LY sequence. The second region was at the $3^{\prime}$ end of the gene and incorporated four different SNPs, with LY containing a guanine or cytosine at the positions while TPPD possessed thymine at each of the four positions (Fig. 1). Based on this, two primer sets were designed to evaluate melting temperature differences between LY and TPPD, one set for the $5^{\prime}$ region and one set for the $3^{\prime}$ region (Table 1 ).

Primer screening and plasmid standards. The initial qPCR test of both primer sets were successful for both LY and TPPD (Table 3). The lower Ct values for the TPPD samples for both primer sets indicated a higher titer of phytoplasma in the sample. In this initial test, HRMA revealed a difference in melting temperature of about $0.6^{\circ} \mathrm{C}$, with the TPPD amplified product having a lower melting temperature than the LY product for the $5^{\prime}$ region primer set and a similar difference in melting temperature, about $0.6^{\circ} \mathrm{C}$, between the corresponding products for the $3^{\prime}$ region primer set (Table 3 ). All reactions for plasmid standard optimization for both primer sets successfully amplified (Tables 4 and 5). For the $5^{\prime}$ region primer set, the average Tm of the amplified product for LY was significantly higher than that of TPPD $(\mathrm{df}=1, \mathrm{~F}=55.99, P \leq 0.0001)$, with LY having a mean Tm of $80.7 \pm$ $0.02^{\circ} \mathrm{C}$ and TPPD having an average Tm of $80.3 \pm 0.02^{\circ} \mathrm{C}$. The $3^{\prime}$ region primer set yielded a similar difference with $\mathrm{LY}$ having a significantly higher Tm than TPPD $(\mathrm{df}=1, \mathrm{~F}=37.77, P \leq 0.0001)$, with $\mathrm{LY}$ having a mean $\mathrm{Tm}$ of $84.5 \pm 0.02^{\circ} \mathrm{C}$ and TPPD having a mean $\mathrm{Tm}$ of $84.1 \pm 0.01^{\circ} \mathrm{C}$. The melt curves generated for the $5^{\prime}$ region primer set demonstrated an observable shift in fluorescence between LY and
Table 3. Quantitative PCR results for the initial screening of the primers designed for high-resolution melt analysis to distinguish lethal yellowing and Texas Phoenix palm decline associated phytoplasmas

\begin{tabular}{|c|c|c|c|c|c|c|}
\hline \multirow[b]{2}{*}{ Sample } & \multicolumn{3}{|c|}{ PP16S-32/PP16S-163 } & \multicolumn{3}{|c|}{$\begin{array}{l}\text { PP16S-1198/ } \\
\text { PP16S-1452 }\end{array}$} \\
\hline & $\mathbf{C t}$ & $\operatorname{Tm}\left({ }^{\circ} \mathrm{C}\right)$ & Result & $\mathbf{C t}$ & $\operatorname{Tm}\left({ }^{\circ} \mathrm{C}\right)$ & Result \\
\hline TPPD (+) S. palmetto & 14.8 & 79.8 & + & 19.9 & 83.5 & + \\
\hline LY (+) C. nucifera & 21.9 & 80.4 & + & 27.9 & 84.1 & + \\
\hline (-) S. palmetto & No $\mathrm{Ct}$ & 76.5 & - & $\mathrm{No} C t$ & 76.9 & - \\
\hline (-) C. nucifera & No $\mathrm{Ct}$ & 67.7 & - & $\mathrm{No} C t$ & 73.2 & - \\
\hline (-) water control & $\mathrm{No} C t$ & 71.1 & - & $\mathrm{No} C t$ & 70.9 & - \\
\hline
\end{tabular}

Table 4. Quantitative PCR results for plasmid standard dilutions for lethal yellowing and Texas Phoenix palm decline for the PP16S-32/PP16S-163 primer set

\begin{tabular}{lccccc}
\hline & \multicolumn{2}{c}{ LY } & & \multicolumn{2}{c}{ TPPD } \\
\cline { 2 - 3 } \cline { 5 - 6 } $\begin{array}{l}\text { Conc. } \\
\text { (Copies/ } \boldsymbol{\mu l})\end{array}$ & $\begin{array}{c}\text { Mean } \\
\mathbf{C t}( \pm \text { SE) }\end{array}$ & $\begin{array}{c}\text { Mean } \\
\text { Tm }( \pm \text { SE })\end{array}$ & & $\begin{array}{c}\text { Mean } \\
\text { Ct }( \pm \text { SE })\end{array}$ & $\begin{array}{c}\text { Mean } \\
\text { Tm }( \pm \text { SE })\end{array}$ \\
\hline $10^{1}$ & $26.7 \pm 0.02$ & $80.7 \pm 0.05$ & & $26.9 \pm 0.02$ & $80.3 \pm 0.04$ \\
$10^{2}$ & $23.6 \pm 0.02$ & $80.6 \pm 0.04$ & & $23.6 \pm 0.02$ & $80.3 \pm 0.04$ \\
$10^{3}$ & $22.3 \pm 0.01$ & $80.6 \pm 0.04$ & & $22.4 \pm 0.01$ & $80.3 \pm 0.04$ \\
$10^{4}$ & $21.4 \pm 0.00$ & $80.7 \pm 0.05$ & & $21.3 \pm 0.01$ & $80.4 \pm 0.04$ \\
$10^{5}$ & $19.2 \pm 0.00$ & $80.7 \pm 0.00$ & & $19.2 \pm 0.00$ & $80.3 \pm 0.00$ \\
$10^{6}$ & $15.4 \pm 0.00$ & $80.9 \pm 0.00$ & & $15.6 \pm 0.00$ & $80.4 \pm 0.00$ \\
$10^{7}$ & $12.2 \pm 0.00$ & $80.8 \pm 0.05$ & & $12.4 \pm 0.00$ & $80.4 \pm 0.00$ \\
$10^{8}$ & $8.6 \pm 0.01$ & $80.8 \pm 0.05$ & & $8.4 \pm 0.01$ & $80.4 \pm 0.00$ \\
$10^{9}$ & $5.4 \pm 0.02$ & $80.7 \pm 0.08$ & & $5.4 \pm 0.01$ & $80.3 \pm 0.00$ \\
$10^{10}$ & $4.6 \pm 0.02$ & $80.6 \pm 0.04$ & & $4.7 \pm 0.01$ & $80.1 \pm 0.00$ \\
Total & n/a & $80.7 \pm 0.02$ & & n/a & $80.3 \pm 0.02$ \\
$(-) \mathrm{H}_{2} \mathrm{O}$ & No Ct & $76.2 \pm 0.0$ & & No Ct & $76.3 \pm 0.00$ \\
\hline & & & & &
\end{tabular}

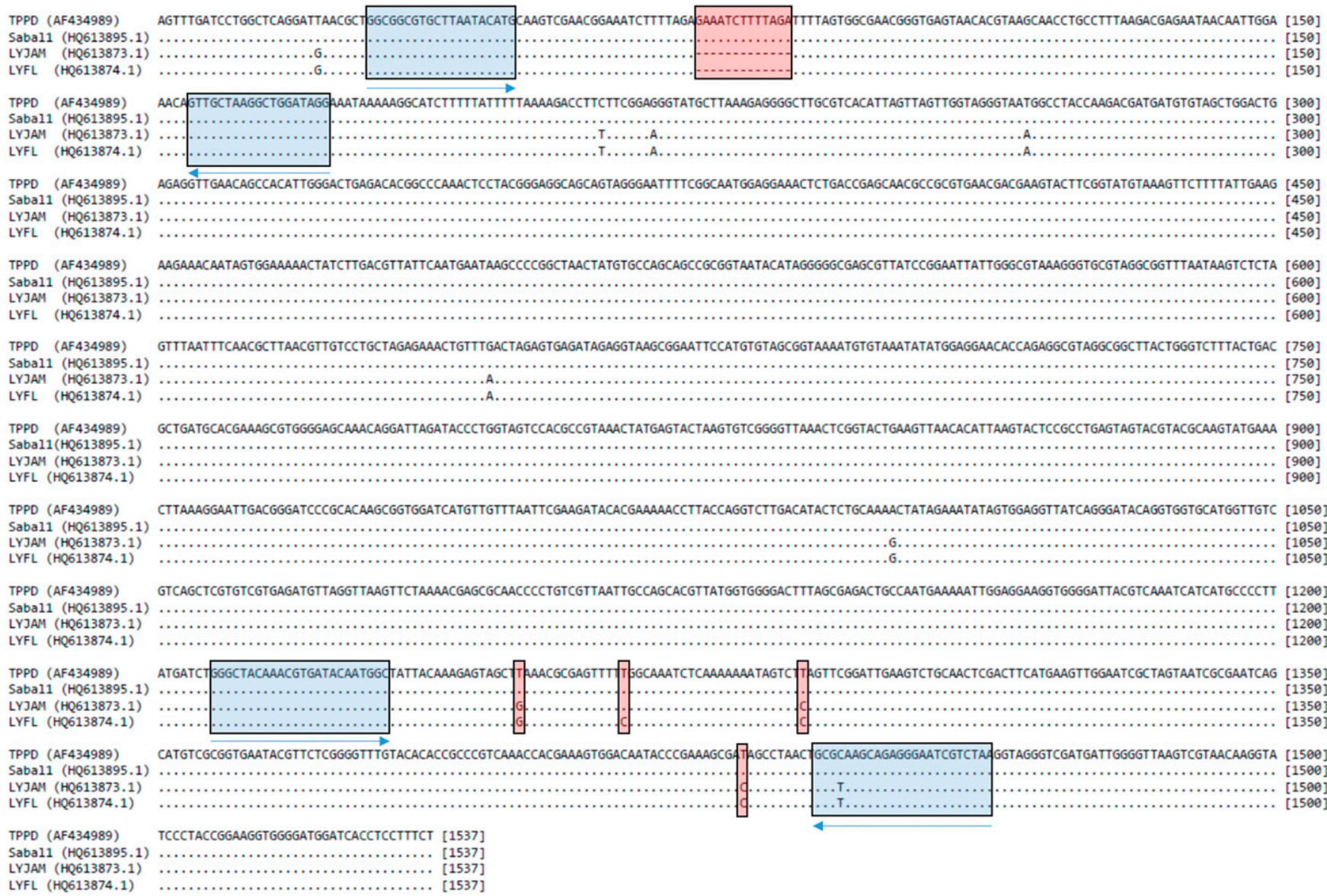

Fig. 1. Sequence alignment for the $16 \mathrm{~S}$ gene of various isolates of $L Y$ and TPPD used for designing primers for $\mathrm{qPCR}$ assays and high resolution melting analysis (HRMA); $5^{\prime} \rightarrow 3^{\prime}$ direction, blue highlight $=$ primer region, red highlight $=$ variable region suitable for HRMA $\rightarrow=$ forward primer, $\leftarrow=$ reverse primer . 
Table 5. qPCR results for plasmid standard dilutions for lethal yellowing and Texas Phoenix palm decline for the PP16S-1198/PP16S-1452 primer set

\begin{tabular}{|c|c|c|c|c|}
\hline \multirow[b]{2}{*}{$\begin{array}{l}\text { Conc. } \\
\text { (Copies/ } \mu \mathrm{l})\end{array}$} & \multicolumn{2}{|c|}{$\mathbf{L Y}$} & \multicolumn{2}{|c|}{ TPPD } \\
\hline & $\begin{array}{c}\text { Mean } \\
\mathrm{Ct}( \pm \mathrm{SE})\end{array}$ & $\begin{array}{c}\text { Mean } \\
\operatorname{Tm}( \pm S E)\end{array}$ & $\begin{array}{c}\text { Mean } \\
\mathrm{Ct}( \pm \mathrm{SE})\end{array}$ & $\begin{array}{c}\text { Mean } \\
\operatorname{Tm}( \pm S E)\end{array}$ \\
\hline $10^{1}$ & $32.2 \pm 0.5$ & $84.4 \pm 0.02$ & $31.0 \pm 0.2$ & $84.1 \pm 0.02$ \\
\hline $10^{2}$ & $28.3 \pm 0.3$ & $84.4 \pm 0.02$ & $28.4 \pm 0.6$ & $84.0 \pm 0.01$ \\
\hline $10^{3}$ & $25.4 \pm 1.1$ & $84.4 \pm 0.01$ & $25.7 \pm 0.3$ & $84.2 \pm 0.01$ \\
\hline $10^{4}$ & $22.1 \pm 0.3$ & $84.5 \pm 0.01$ & $22.5 \pm 0.0$ & $84.2 \pm 0.01$ \\
\hline $10^{5}$ & $19.7 \pm 0.1$ & $84.6 \pm 0.01$ & $18.5 \pm 0.6$ & $84.1 \pm 0.01$ \\
\hline $10^{6}$ & $16.0 \pm 0.1$ & $84.7 \pm 0.01$ & $15.6 \pm 0.1$ & $84.2 \pm 0.01$ \\
\hline $10^{7}$ & $11.4 \pm 0.3$ & $84.6 \pm 0.01$ & $11.4 \pm 0.3$ & $84.2 \pm 0.01$ \\
\hline $10^{8}$ & $8.8 \pm 0.5$ & $84.6 \pm 0.01$ & $8.0 \pm 0.2$ & $84.2 \pm 0.01$ \\
\hline $10^{9}$ & $5.9 \pm 0.3$ & $84.4 \pm 0.02$ & $5.2 \pm 0.1$ & $84.0 \pm 0.02$ \\
\hline $10^{10}$ & $4.6 \pm 0.0$ & $84.4 \pm 0.02$ & $3.9 \pm 0.1$ & $84.0 \pm 0.02$ \\
\hline Total & $18.8 \pm 9.6$ & $84.5 \pm 0.02$ & $18.5 \pm 8.8$ & $84.1 \pm 0.01$ \\
\hline (-) $\mathrm{H}_{2} \mathrm{O}$ & No Ct & $76.2 \pm 0.0$ & No Ct & $76.3 \pm 0.00$ \\
\hline
\end{tabular}

TPPD (Fig. 2). Additionally, an observable shift in fluorescence was seen between LY and TPPD for the 3' region primer set (Fig. 2). No amplification was detected for water controls (no $\mathrm{Ct}$ ) in the plasmid assays for either primer set.

Isolate screening. For the various isolates of TPPD and LY screened, all samples across all replicates produced an amplicon using both the $5^{\prime}$ region and $3^{\prime}$ region primer sets (Table 6 and 7). For the $5^{\prime}$ region primer set, the mean $\mathrm{Tm}$ for all isolates of $\mathrm{LY}$ was $80.8 \pm$ $0.07^{\circ} \mathrm{C}$ and was significantly higher $(\mathrm{df}=1, \mathrm{~F}=38.27, P=0.0002)$ than the mean Tm of TPPD for the same region amplified, $80.3 \pm$ $0.02^{\circ} \mathrm{C}$. Also, for the $3^{\prime}$ region primer set, the mean $\mathrm{Tm}$ for all isolates of LY was $84.7 \pm 0.00^{\circ} \mathrm{C}$ and was significantly higher $(\mathrm{df}=1, \mathrm{~F}=$ 22.94, $P=0.001$ ) than the mean Tm for all TPPD isolates, $84.3 \pm$ $0.00^{\circ} \mathrm{C}$. For all isolates of LY and TPPD, the $5^{\prime}$ region primer set also demonstrated distinct melt curves relative to each other that fit the curve of the respective plasmid standards for the region amplified (Fig. 2). The same pattern was observed with the $3^{\prime}$ region primer set for isolates of LY and TPPD, where the corresponding melt

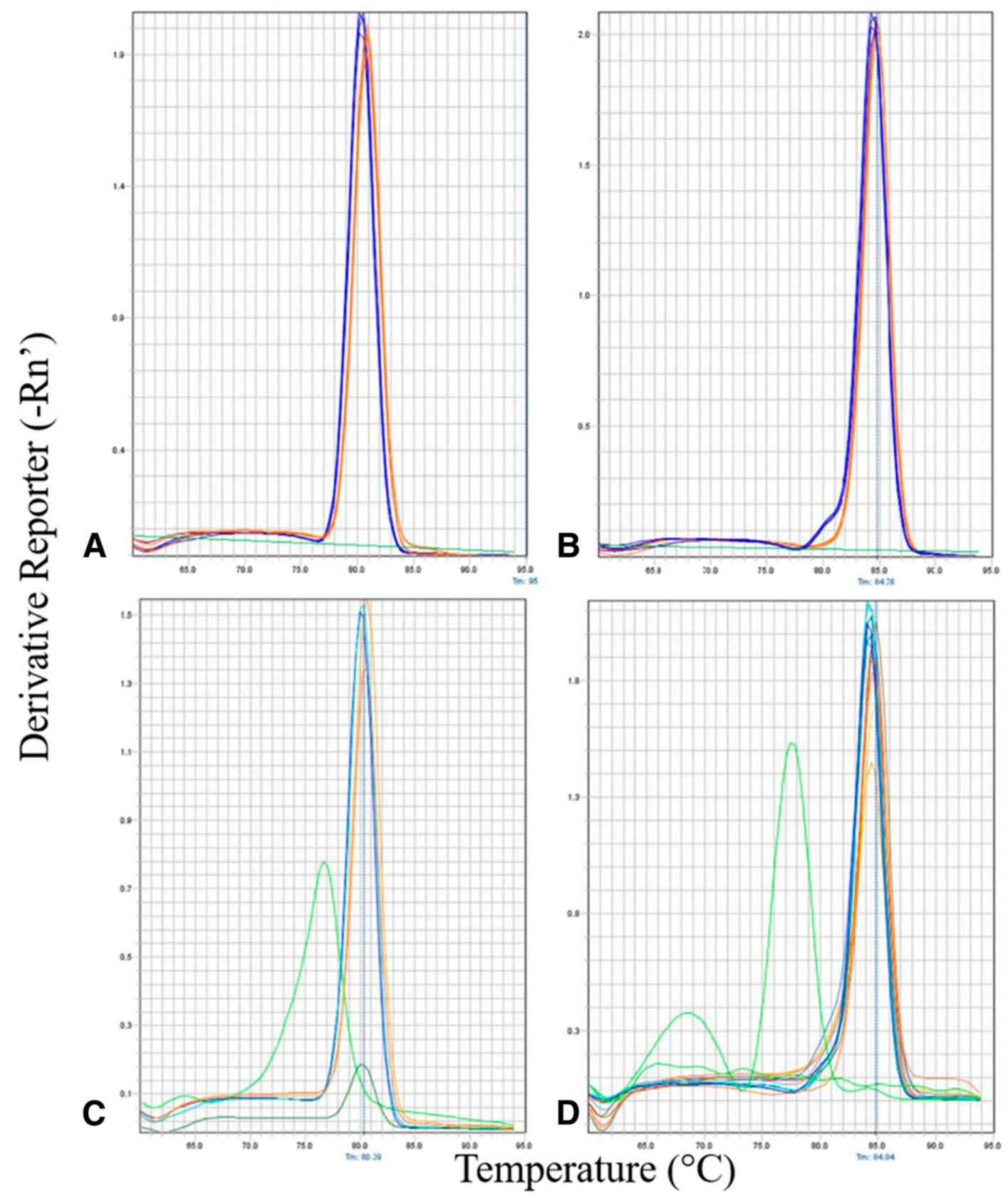

Fig. 2. Melt curve analysis of the $5^{\prime}$ primers based on plasmid standard test (A), $3^{\prime}$ primers based on plasmid standard test (B), $5^{\prime}$ primers based on isolate tests (C), and $3^{\prime}$ primers based on isolate tests $(\mathbf{D})$ demonstrating derivative fluorescence data: orange curve (large curve, right skewed) $=$ LY, blue curve (large curve, skewed left) $=$ TPPD, green curve $=$ negative control. 
Table 6. Quantitative PCR results for isolates of lethal yellowing and Texas Phoenix palm decline obtained from infected Cocos nucifera and Sabal palmetto with the PP16S-32/PP16S-163 primer set

\begin{tabular}{llccr}
\hline Sample ID & Disease & Mean Ct $( \pm$ SE) & Mean Tm $( \pm$ SE) & Result \\
\hline EF-509 & LY & $23.1 \pm 0.05$ & $80.8 \pm 0.00$ & + \\
PSA & LY & $24.0 \pm 0.05$ & $80.7 \pm 0.01$ & + \\
IOJT & LY & $26.3 \pm 0.04$ & $80.6 \pm 0.02$ & + \\
RCP1 & LY & $19.0 \pm 0.06$ & $81.0 \pm 0.01$ & + \\
SWCP & LY & $24.6 \pm 0.02$ & $80.7 \pm 0.01$ & + \\
All isolates & LY & $23.4 \pm 1.2$ & $80.8 \pm 0.07$ & \\
Sab1+C & TPPD & $18.9 \pm 0.01$ & $80.3 \pm 0.01$ & + \\
RDSOP & TPPD & $23.0 \pm 0.01$ & $80.2 \pm 0.00$ & + \\
DLM & TPPD & $20.0 \pm 0.04$ & $80.3 \pm 0.01$ & + \\
GPL-PS & TPPD & $17.8 \pm 0.01$ & $80.3 \pm 0.00$ & + \\
SP4 & TPPD & $16.5 \pm 0.00$ & $80.3 \pm 0.00$ & + \\
All isolates & TPPD & $19.2 \pm 1.1$ & $80.3 \pm 0.02$ & \\
LY-plasmid & LY & 21.5 & 80.2 & + \\
TPPD-plasmid & TPPD & 21.0 & 80.7 & + \\
(-) control & Healthy & No Ct & 76.3 & - \\
Water control & n/a & No Ct & 79.1 & - \\
\hline
\end{tabular}

Table 7. Quantitative PCR results for isolates of lethal yellowing and Texas Phoenix palm decline obtained from infected Cocos nucifera and Sabal palmetto with the PP16S-1198/PP16S-1452 primer set

\begin{tabular}{llccr}
\hline Sample ID & Disease & Mean Ct $( \pm$ SE) & Mean Tm $( \pm$ SE) & Result \\
\hline EF-509 & LY & $27.9 \pm 0.4$ & $84.7 \pm 0.01$ & + \\
PSA & LY & $30.6 \pm 0.03$ & $84.7 \pm 0.01$ & + \\
IOJT & LY & $31.0 \pm 0.1$ & $84.7 \pm 0.01$ & + \\
RCP1 & LY & $25.7 \pm 0.1$ & $84.7 \pm 0.01$ & + \\
SWCP & LY & $28.9 \pm 0.2$ & $84.7 \pm 0.01$ & + \\
Sab1+C & TPPD & $21.0 \pm 0.01$ & $84.3 \pm 0.01$ & + \\
RDSOP & TPPD & $27.7 \pm 0.2$ & $84.3 \pm 0.01$ & + \\
DLM & TPPD & $22.7 \pm 0.2$ & $84.3 \pm 0.01$ & + \\
GPL-PS & TPPD & $24.1 \pm 0.1$ & $84.3 \pm 0.01$ & + \\
DLC3 & TPPD & $19.9 \pm 0.3$ & $84.3 \pm 0.01$ & + \\
LY-plasmid & LY & 21.9 & 84.7 & + \\
TPPD-plasmid & TPPD & 21.4 & 84.3 & + \\
(-) control & Healthy & No Ct & 71.2 & - \\
Water control & n/a & No Ct & 71.3 & - \\
\hline
\end{tabular}

curves fit those of the plasmid standards (Fig. 2). All amplicons generated from isolates were sequenced and aligned for both the $5^{\prime}$ region (Fig. 2) and 3' region (Fig. 2) for LY and TPPD isolates to verify their identities. All isolates for both LY and TPPD exhibited the variation at both the $5^{\prime}$ and $3^{\prime}$ regions (Fig. 3).

\section{Discussion}

Traditionally, differentiation of TPPD and LY has been based on RFLP analysis of the 16S gene (Brown et al. 2006; Harrison et al. 2008). While this technique is useful from a taxonomic and research perspective, it is not practical as a diagnostic tool due to the amount of time and resources necessary to obtain the data. Additionally, the post PCR steps necessary for restriction enzymes in RFLP increases risk of error in data collection and identification.

This study demonstrates the utility of qPCR and HRMA in the detection and differentiation of the two strains of phytoplasma that are associated with LY and TPPD in the state of Florida. Both primer sets consistently amplified both strains of phytoplasma and demonstrated a consistent difference in Tm of the corresponding amplified products from isolates from different localities. This assay provides a means to detect and differentiate LY and TPPD that reduces time, resources, and cost. The relatively low $\mathrm{Ct}$ values (about 27) generated from the $10^{1}$ copies/ $\mu$ l in Tables 4 and 5 are likely due to the Qubit not being as accurate as other systems for quantification, which would result in $\mathrm{Ct}$ values deviating from what the true value would be. Because of this, even further dilutions would potentially produce $\mathrm{Ct}$ values. While this is a shortcoming in this study, accurate quantification was not the goal of the study but to see if template concentration impacted $\mathrm{Tm}$ of the amplified product. While quantity presented is not likely as accurate as it could be, it clearly demonstrates that there was a spectrum of concentration from very high to very low that showed no measurable difference of Tm of the amplified product.

By utilizing qPCR and HRMA, the assay allows for the detection of phytoplasma and differentiation in the same reaction that is monitored in real time rather than visualizing the results on a gel after each step. This eliminates the need to run product on a gel, digestion with restriction enzymes, and running again on another gel. By eliminating post-PCR processing steps, costs are significantly reduced because less materials and resources are used as well as a significant decrease in time spent on the assays by personnel, allowing other work to be accomplished. Being able to generate this type of data
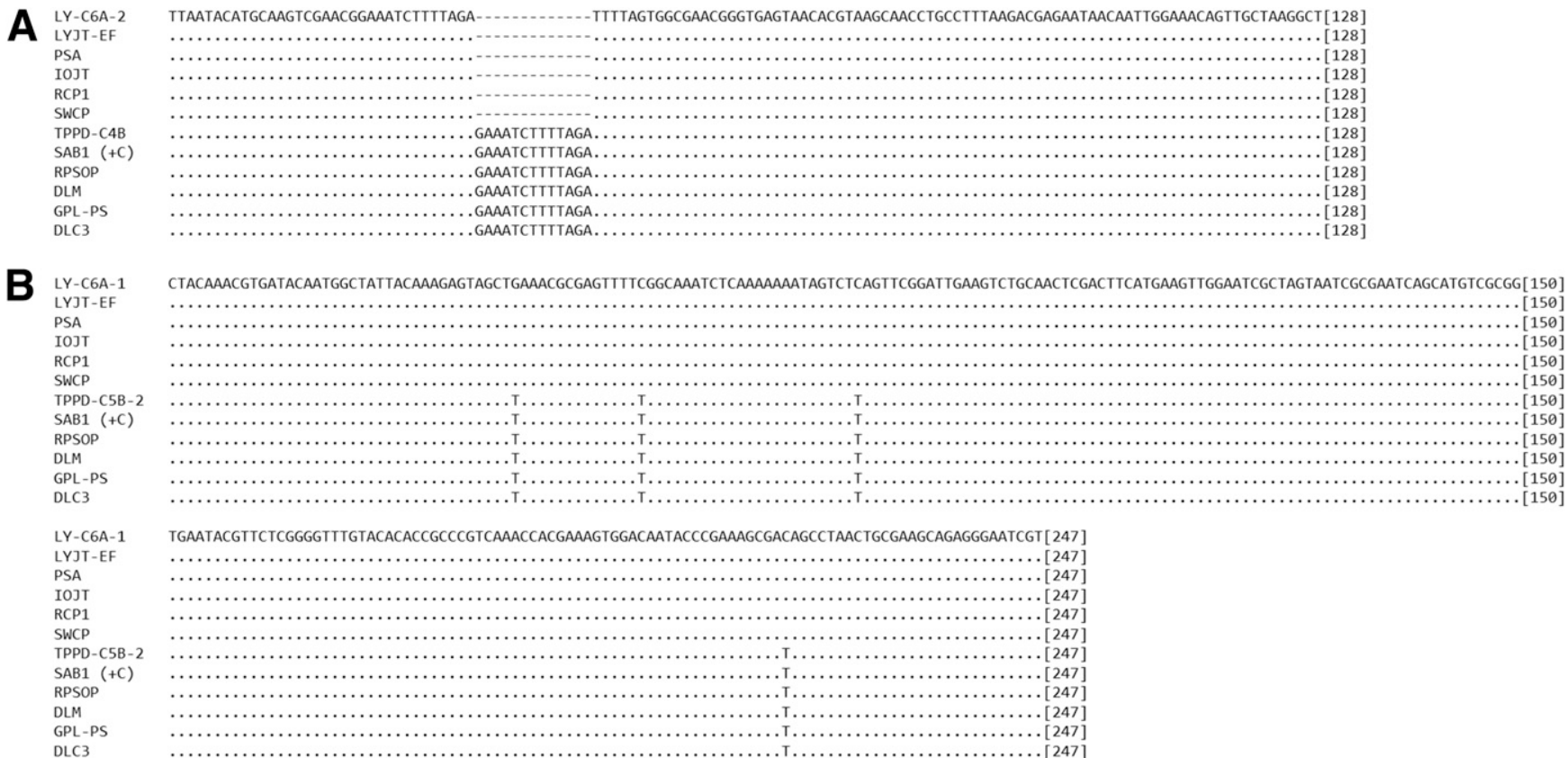

Fig. 3. Sequence alignment for all isolates and plasmid standards used in HRMA analysis for the $5^{\prime}$ region using primers PP16S-29 and PP16S-173 demonstrating a 13 bp insertion/deletion (A) and for the $3^{\prime}$ region using primers PP16S-1198 and PP16S-1452 demonstrating four single nucleotide polymorphisms (B). 
faster also has a potential economic benefit for stakeholders because if they are aware of the problem quickly, they can implement management strategies (antibiotics or tree removal) sooner and possibly prevent the spread of the phytoplasma to nearby palms, ultimately reducing or eliminating outbreaks. Tree removal and antibiotics could be implemented regardless of the subgroup present in sample, but knowing the subgroup present could help guide vector management. Currently, the vector of the subgroup-D phytoplasma is unknown and the putative vector of the subgroup-A phytoplasma is Haplaxius crudus (Howard and Thomas 1980; Howard et al. 1983). The range of both LY (subgroup-A) and H. crudus is restricted to the southern portion of Florida (Harrison and Elliott 2015) while TPPD (subgroup-D) occurs much further north (Harrison and Elliott 2016) where $H$. crudus has not been recorded, suggesting different vector species. By rapidly identifying the subgroup present, a quicker response can be implemented that specifically targets the biology of the vector that could aid in reducing the rate of spread. Future research needs to identify the vector of the subgroup-D phytoplasma and verify the status of $H$. crudus as a vector of the subgroup-A phytoplasma. Consequently, the protocol described herein may aid in phytoplasma detection and identification in candidate vector species, thus contributing to the vector discovery process. While qPCR assays have been developed for TPPD (subgroup D), LY (subgroup A), and subgroup E (Córdova et al. 2014), this is the first use of HRMA in palm-infecting phytoplasmas, and to the authors' knowledge, the first use for phytoplasma differentiation.

This tool is useful for researchers and a benefit to stakeholders in Florida as well as other regions where both LY and TPPD are present and a threat to the sustainability of palm production. Future efforts need to expand these assays to include other strains of phytoplasma present throughout the Americas (Córdova et al. 2014) as well as incorporate strains found in palms throughout Africa (Mpunami et al. 1999) and Asia (Nejat et al. 2010). As the body of knowledge grows about the true diversity of phytoplasmas infecting palms and ease in full genome sequencing of phytoplasmas increases, qPCR assays with HRMA can be adapted to target all known strains to give a highly sensitive and rapid means to detect and identify phytoplasmas in palms.

\section{Acknowledgments}

Funding for this research was provided through the Farm Bill Cooperative Agreement 15-8130-0148-CA. The authors would like to thank Seemanti Chakrabati for technical assistance in the laboratory.

\section{Literature Cited}

Arellano, J., and Oropeza, C. 1995. Lethal Yellowing. Pages 1-15 in: Lethal yellowing: research and practical aspects. Kluwer Academic Publishers, Dordrecht, The Netherlands.

Bahder, B. W., Zalom, F. G., and Sudarshana, M. R. 2016. An evaluation of the flora adjacent to wine grape vineyards for the presence of alternative host plants of grapevine red blotch- associated virus. Plant Dis. 100:1571-1574.

Bester, R., Jooste, A. E. C., Maree, H. J., and Burger, J. T. 2012. Real-time RTPCR high- resolution melting curve analysis and multiplex RT-PCR to detect and differentiate grapevine leafroll-associated virus 3 variant groups I, II, III, and VI. Virol. J. 9:219.

Brown, S. E., Been, B. O., and McLaughlin, W. A. 2006. Detection and variability of the lethal yellowing group (16Sr IV) phytoplasmas in the Cedusa sp. (Hemiptera: Auchenorrhyncha: Derbidae) in Jamaica). Ann. Appl. Biol. 149:53-62.
Corbett, M. K. 1959. Diseases of the coconut palm. I. lethal yellowing or unknown disease. Principes J. Palm Soc. 3:5-13.

Córdova, I., Oropeza, C., Puch-Hau, C., Harrison, N., Collí-Rodríguez, A., Narvaez, M., Nic-Matos, G., Reyes, C., and Sáenz, L. 2014. A real-time PCR assay for detection of coconut lethal yellowing phytoplasmas of group 16SrIV subgroups A, D, and E found in the Americas. J. Plant Pathol. 96: 343-352.

Duduk, B., and Bertaccini, A. 2011. Phytoplasma classification: Taxonomy based on 16S ribosomal gene, is it enough? Phytopathogenic Mollicutes 1:3-13.

Fawcett, W. 1891. Report on the coco-nut disease at Montego Bay. Bull. Bot. Dep. Jamaica 23:2.

Harrison, N. A., Bourne, C. M., Cox, R. L., Tsai, J. H., and Richardson, P. A. 1992. DNA probes for detection of myscoplasmalike organisms associated with lethal yellowing disease of palms in Florida. Phytopathology 82:216-224.

Harrison, N. A. and Elliott, M. L. 2015. Lethal yellowing (LY) of palm. UF/IFAS Extension document PP-222.

Harrison, N. A. and Elliott, M. L. 2016. Texas Phoenix palm decline. UF/IFAS Extension document PP-243.

Harrison, N. A., Helmick, E. E., and Elliott, M. L. 2008. Lethal yellowing-type diseases of palms associated with phytoplasma newly identified in Florida, USA. Ann. Appl. Biol. 153:85-94.

Harrison, N. A., Helmick, E. E., and Elliott, M. L. 2009. First report of a phytoplasma-associated lethal decline of Sabal palmetto in Florida, USA. Plant Pathol. 58:792.

Harrison, N. A., Myrie, W., Jones, P., Carpio, M. L., Castillo, M., Doyle, M. M., and Oropeza, C. 2002a. 16S rRNA interoperon sequence heterogeneity distinguishes strain populations of palm lethal yellowing phytoplasma in the Caribbean region. Ann. Appl. Biol. 141:183-193.

Harrison, N. A., Womack, M., and Carpio, M. L. 2002b. Detection and characterization of a lethal yellowing (16SrIV) group phytoplasma in Canary island date palms affected by lethal decline in Texas. Plant Dis. 86: 676-681.

Howard, F. W., Norris, R. C., and Thomas, D. L. 1983. Evidence of transmission of palm lethal yellowing agent by a planthopper, Myndus crudus (Homoptera: Cixiidae). Trop. Agric. (St Augustine) 60:168-171.

Howard, F. W., and Thomas, D. L. 1980. Transmission of palm lethal decline to Veitchia merrillii by a planthopper Myndus crudus. J. Econ. Entomol. 73: 715-717.

Khachatryan, H. and Hodges, A. W. 2014. Florida nursery crops and landscaping industry economic impacts, situation, and outlook. UF/IFAS Extension document FE946.

Kumar, S., Stecher, G., and Tamura, K. 2016. MEGA7: Molecular Evolutionary Genetics Analysis version 7.0 for bigger datasets. Mol. Biol. Evol. 33: $1870-1874$

Luchi, N., Pratesi, N., Simi, L., Pazzagli, M., Capretti, P., Scala, A., Slippers, B., and Pinzani, P. 2011. High-Resolution Melting Analysis: a new molecular approach for the early detection of Diplodia pinea in Austrian pine. Fungal Biol. 115:715-723.

McCoy, R. E., Miller, M. E., Thomas, D. L., and Amador, J. 1980. Lethal decline of Phoenix palms in Texas associated with mycoplasmalike organisms. Plant Dis. 64:1038-1040.

Mpunami, A. A., Tymon, A., Jones, P., and Dickinson, M. J. 1999. Genetic diversity in the coconut lethal yellowing disease phytoplasmas of east Africa Plant Pathol. 48:109-114.

Nejat, N., Sijam, K., Abdullah, S. N. A., Vadamalai, G., Sidek, Z., and Dickinson, M. 2010. Development of a TaqMan real-time PCR for sensitive detection of the novel phytoplasma associated with coconut yellow decline in Malaysia. J. Plant Pathol. 92:769-773.

Varga, A., and James, D. 2006. Real-time RT-PCR and SYBR Green I melting curve analysis for the identification of Plum pox virus strains C, EA, and W: effect of amplicon size, melt rate, and dye translocation. J. Virol. Methods 132:146-153.

Vossen, R. H. A. M., Aten, E., Roos, A., and den Dunnen, J. T. 2009. HighResolution Melting Analysis (HRMA)-more than just sequence variant screening. Hum. Mutat. 30:860-866. 